JOURNAL OF THE AMERICAN SOCIETY FOR INFORMATION SCIENCE. Volume 42, issue 2 (March 1991), p. 137138 @ 1991 by John Wiley \& Sons, Inc.

ISSN: 0002-8231 DOI: 10.1002/(SICI)1097-4571(199103)42:2<137::AID-ASI14>3.0.CO;2-7

\title{
Part II. A Model Academic Integrated Information Center The Setting for the Project
}

\section{Joseph Branin}

Director, Humanities \& Social Sciences Libraries, University of Minnesota, Minneapolis, MN 55455

\section{Charles Finn}

Manager, Information Resources, Hubert H. Humphrey Institute of Public Affairs, University of Minnesota, Minneapolis, MN 55455

This article describes the academic unit for which the model IIC was developed and the information environment within which the IIC would operate.

\section{The Hubert H. Humphrey Institute of Public Affairs}

The model IIC was designed to serve the Hubert H. Humphrey Institute of Public Affairs at the University of Minnesota. The Humphrey Institute is a free standing academic unit administered by a dean who reports to the Vice President for Academic Affairs. As the graduate school of public affairs for the University of Minnesota, the Institute offers master's degrees in public affairs and planning with approximately 130 graduate students enrolled. It operates an interdisciplinary network for basic and applied research on matters of public policy and the practice of public affairs. It provides advanced education in leadership for experienced public administrators, and manages an active program of general public affairs education, outreach, and service for the broader community.

The Institute has 16 regular faculty, 10 resident senior fellows (reflective practitioners who participate in teaching, research, or service programs, but do not hold regular faculty appointments), and 34 adjunct faculty both from within the University (20) and from other institutions and agencies (14). The disciplinary areas covered by the regular faculty and senior fellows include planning, public administration, law, urban studies, geography, political science, economics, sociology, social work, social ethics, theology, medicine, and physics. The Institute supports six research centers - the Strategic Planning and Management Research Center (with the Carlson School of Management and the Department of Agricultural and Applied Economics), the State and Regional Research Center (with the Department of Agricultural and Applied Economics and the Department of Geography), the Center for the Study of Youth Policy, the Center on Women and Public Policy, the Center for Population Analysis and Policy, and the Environmental Policy Center. The Institute is served by the Public Affairs Library, a branch of University Libraries located within the Institute.

The Humphrey Institute was selected as the site for the project for two reasons. First, the Institute is composed of faculty with diverse interdisciplinary backgrounds and research interests that cut across traditional academic boundaries. Second, the Institute requires information resources and services that extend beyond any single collection or service unit. The Institute represents in microcosm the interdisciplinary thrust of modern scholarship. While the model IIC that was developed for the Humphrey Institute addresses the unique requirements of the Institute, it is anticipated that the model might be relevant to other academic units that share similar characteristics with the Institute. 


\section{The Information Environment at the University of Minnesota}

The University of Minnesota, Twin Cities Campus, comprises an academic community of more than 60,000 faculty, staff, and students located on three campuses in the Twin Cities of Minneapolis and Saint Paul. It is one of the foremost research universities in the nation consistently ranking among the top 10 universities in the amount of federally funded research.

The University's information accessing and processing requirements are currently served by three separate systems: University Libraries which provides scholarly information; Academic Computing Services and Systems which provides academic computing and information services; and Administrative Information Services which provides administrative computing and information services. The University has in place an integrated voice and data telecommunications system that has the technical capability to provide interactive data services to the desks of faculty. The University has the capability to integrate its various information systems into an interactive information services environment. Many departments currently have local area networks, and a University objective is to connect these networks with central systems for the provision of information services and electronic mail. However, the administrative decision to begin integration of information systems and services and the issues of administrative control of integrated information systems and services on campus are complicated by both the collegial governance structure of the University and vested interests in maintaining the autonomy of the three separate systems. University Libraries and Academic Computing report to the Vice President for Academic Affairs while Administrative Information Services reports to the Vice President for Finance and Physical Planning. At the present time none of these systems, having neither the mandate nor the resources, is positioned to assume responsibility for unit level information management. In addition, the proliferation of end-user computing on campus has engendered a great variety of decentralized school or departmental information support units for microcomputer management and applications that are controlled and supported by the academic units which initiated them. In this environment, the initiative for the development of IICs has passed to local academic units.

\section{University Libraries}

Within this environment, University Libraries, a system of more than 30 libraries containing more than four million volumes, has embarked on a major program to enhance its capabilities to deliver reference and information services to any site on campus. In the Fall of 1987, an online catalog, LUMINA (Libraries of the University of Minnesota Integrated Network Access), was implemented and made available to faculty, students, and staff from terminals on campus. LUMINA provides access to the bibliographic file and is supported by document delivery to faculty offices throughout the Twin Cities campus. In 1988 LUMINA became available on a dial-up basis. University Libraries and Administrative Information Services, which provides access to LUMINA via its computers, have begun planning for the provision of additional information services to end users such as providing access to machine-readable databases including those that are produced and managed on campus and those, both public and proprietary, that are available through vendors off campus. It is anticipated that this state-of-theart information environment will be conducive to the development of information centers on campus and will have profound effects upon the research and teaching missions of the University as well as upon the organization and management of the information function on campus. 


\section{Academic Computing Services and Systems}

The mission of Academic Computing is to provide for the computing needs of faculty and students and the University. All main frame and general personal computing resources at the University dedicated to support of research and teaching are administered through this organization. The traditional responsibilities of Academic Computing were in the areas of mainframe computing, but the demands of their users have changed its composition from largely a supporter of mainframe computing to database and telecommunications support. ACSS will largely be responsible for development of the network "backbone" that will link most of the computer networks at the University during the next few years.

\section{Administrative Information Services}

The mission of Academic Information Services is to manage the administrative information systems for the University. These systems include admissions, registration, student records, alumni records and fundraising, personnel, payroll, accounting, physical plant and inventory, among others. Administrative Information Services manages its own mainframes to support these systems. These systems currently are neither linked nor necessarily compatible. 